\title{
“Eles já nascem sabendo!": desmistificando o conceito de nativos digitais no contexto educacional
}

\author{
Magda Pischetola ${ }^{1}$, Bruna Damiana Heinsfeld ${ }^{2}$ \\ ${ }^{1}$ Departamento de Educação - PUC-Rio \\ ${ }^{2}$ Departamento de Educação - PUC-Rio \\ magda@puc-rio.br; brunadamiana@gmail.com
}

\begin{abstract}
Resumo:
O desenvolvimento das tecnologias digitais trouxe grandes mudanças tanto nas formas de produção socioculturais quanto nos modelos comunicacionais e nas dinâmicas de participação cidadã. A educação, enquanto parte da sociedade, não se isenta dessas mudanças: as linguagens midiáticas transformam o conceito de letramento e abrem novos caminhos para a aprendizagem, crescendo a relevância da compreensão dessas dinâmicas. Neste trabalho, apresentamos os resultados de uma pesquisa qualitativa desenvolvida entre 2014 e 2016 em oito escolas municipais do Rio de Janeiro, com o objetivo de identificar e analisar as percepções dos docentes quanto às habilidades consideradas como essenciais para um uso eficaz e significativo das tecnologias. Para tanto, utilizamos a descrição de van Dijk (2005) sobre as habilidades que constituem o letramento digital. Percebe-se que as habilidades dos alunos com o uso de tecnologias são valorizadas apenas do ponto de vista técnico, não sendo exploradas as habilidades informacionais e estratégicas. Emergem, então, dois desafios principais para a educação: a revisão do conceito de letramento, abarcando as novas linguagens e habilidades do mundo contemporâneo, e a reformulação do papel do professor e, consequentemente, de sua prática pedagógica, em prol da mediação.
\end{abstract}

Palavras-chave: educação; tecnologias; letramento digital; nativos digitais

\section{"They are born knowing!": Demystifying the concept of digital natives in the educational context}

\begin{abstract}
:
The development of digital technologies has brought about significant changes both in socio-cultural forms of production and communication models and in the dynamics of civic participation. Education, integrated with society, is not exempt from these changes: media languages transform the literacy concept and open new avenues for learning, increasing the relevance of understanding these dynamics. In this work, we present the results of qualitative research developed between 2014 and 2016 in eight municipal schools in Rio de Janeiro, aiming to identify and analyse teachers' perceptions on the skills considered to be essential for effective and meaningful use of technologies. To do so, we use van Dijk's (2005) description of the skills that constitute digital literacy. We noticed that the students' abilities with the use of technologies are valued only from the technical point of view, disregarding informational and strategic skills. Therefore, two main challenges emerge for education: the revision of the literacy concept, embracing new languages and skills of the contemporary world, and the reformulation of the teacher's role and, consequently, of the pedagogical practices, in favour of mediation.
\end{abstract}

Keywords: education; technologies; digital literacy; digital natives 


\section{Introdução}

As Tecnologias da Informação e da Comunicação (TIC) aportaram grandes mudanças na sociedade, nas formas de produção socioculturais, nos modelos comunicacionais e no comércio, nas dinâmicas de participação cidadã e política, na definição dos equilíbrios de poder. A educação, enquanto parte da sociedade, não é imune a essas mudanças: as linguagens midiáticas transformam o conceito de autoria, de alfabetização, de letramento, e a Internet abre novos caminhos de pesquisa e, potencialmente, de aprendizagem. A possibilidade do acesso à informação é ampliada graças aos dispositivos de comunicação móvel e os ambientes virtuais de aprendizagem permitem a colaboração mutua e o compartilhamento de informação em tempo real.

Pesquisas recentes destacam, porém, que a instituição escola presenta ainda uma dificuldade substancial em integrar as TICs em seu cotidiano, apresentando uma configuração de práticas e organização atrelada aos métodos tradicionais de ensino e aprendizagem (BRASILINO, 2017; GATTI; BARRETO, 2009; RIEDNER, 2018). Conforme Bannell et al., em muitos casos, os espaços físicos da escola apresentam rigidez estrutural, com a disposição dos alunos em fileiras. A atenção da aula está focada no quadro no qual o professor muitas vezes escreve de costas para os alunos, marcando uma divisão de papeis evidente. No geral, afirmam, a tendência da escola é a de proporcionar soluções preconstituídas, menosprezando a capacidade de pesquisa e de descoberta do sujeito que aprende e limitando a pluralidade de soluções possíveis para um mesmo problema.

Está entre as crenças que fundamentam as práticas escolares a tese de que o desenvolvimento cognitivo se dá principalmente na relação com o conteúdo curricular, preestabelecido pelos programas ministeriais, que também tendem a indicar os procedimentos que garantem a assimilação desses conteúdos. A diversidade e a riqueza dos estímulos do ambiente simbólico e sócio-cultural ao qual a criança pertence são reduzidas a uma única interpretação da história, da sociedade e do mundo. (BANNELL et al., 2016, p. 92)

Nesse formato, a sala de aula perde o potencial de tornar-se um lugar de compartilhamento de saberes e experiência de diálogo, que acreditamos serem os elementos fundamentais da construção de pensamento crítico. A participação do aluno no processo de ensino e aprendizagem é limitada à leitura e a recepção de conteúdos, raramente entendida como produção e criação autoral. As habilidades dos jovens alunos com o uso de tecnologias são valorizadas do ponto de vista técnico, mas não cultural (HEINSFELD; PISCHETOLA, 2017; NAUMANN; PISCHETOLA， 2017; PISCHETOLA, 2016). Porém, ao mesmo tempo, afirma-se a prerrogativa que os jovens têm de ser muito habilidosos com as tecnologias. Sua habilidade de manuseio das ferramentas é considerada uma vantagem substancial para o mundo atual, a base para todas as competências de desenvolvimento necessário no século XXI. Trata-se das gerações de "nativos digitais", termo cunhado por Prensky em 2001 e reformulado pelo mesmo autor em 2009 em "sábios digitais".

Neste trabalho, apresentamos os resultados de uma pesquisa qualitativa desenvolvida entre 2014 e 2016 em oito escolas municipais de ensino fundamental da cidade do Rio de Janeiro. As percepções dos professores sobre as práticas de seus alunos destacam um entendimento dos jovens como "nativos digitais", sinalizando a facilidade que eles têm para o uso de tecnologias, em oposição à defasagem da escola e do mesmo professor, "imigrante digital" nesse mundo em que as formas de comunicação estão em constante mudança. A partir dos resultados, o artigo reflete sobre a necessidade de 
superarmos o discurso de senso comum e problematiza o papel do professor com respeito à orientação pedagógica de seus alunos.

\section{O mito dos nativos digitais}

Desde 2001, popularizou-se o termo "nativos digitais", criado por Prensky (2001) para definir os jovens da contemporaneidade, uma geração muito hábil no uso das mídias digitais e no acesso aos recursos on-line. Pais e professores, pertencentes a um mundo em que o papel era o suporte de leitura e escrita mais utilizado, mostram sua admiração pelas conquistas dos jovens em termos de softwares instalados e aprendidos, jogos on-line, práticas de compartilhamento e de produção impensáveis há alguns anos, e em constante evolução. Frente a tantas novidades, as agências clássicas de educação - in primis a família e a escola -, "imigrantes digitais", sentem-se defasadas e incapazes de competir com as práticas culturais que as tecnologias providenciam para os jovens.

Mas o que significa exatamente ser nativo digital? A comparação do autor vem da área de linguística, em que um falante nativo não somente apresentaria fluência única e inequívoca em sua língua nativa, mostrando um amplo leque comunicativo, mas também seria dotado de intuições com relação à possibilidade de novas produções e arranjos linguísticos e sua aceitabilidade na língua (DAVIES; ELDER, 2004). Ou seja, sob essa perspectiva, nativo digital é aquele que, além de possuir uma fluência única com relação às TICs, possui habilidade de produzir, (res)significar e remixar conteúdos digitais.

Estudos realizados na área de mídias e educação nos últimos anos mostram que as demandas técnicas das novas interfaces tecnológicas são significativas e que isso pode ter instigado os educadores a concluírem que os jovens já sabem tudo o que precisam para se valer de todas as potencialidades dessas tecnologias (GEE, 2010; LIVINGSTONE, 2011; LEMKE, 2010). Contudo,

O uso intenso das TICs pelos jovens, apesar de estar ampliando as oportunidades de acesso ao conhecimento, ainda não configurou novas práticas autônomas de autoinstrução e não parece estar produzindo os resultados esperados no que diz respeito à ampliação do desempenho escolar. (PISCHETOLA, 2016, p. 40)

Concordamos com Livingstone (2011) quando afirma que o verdadeiro desafio para a educação não é a técnica, mas o uso de tecnologias com foco informativo e educativo. Em outras palavras, diz a autora, precisamos rever o significado atual de letramento, para que possa incluir habilidades que pertencem a outros registros linguísticos. Um breve excurso da evolução do termo letramento pode auxiliar no entendimento da mitologia que está por trás do discurso sobre os "nativos digitais".

Nos anos 1980 começou-se a destacar a importância da alfabetização informática e das habilidades necessárias para o uso do computador. Dez anos depois, o conceito evoluiu para o de alfabetização informacional, incluindo outras capacidades para além das técnicas, como por exemplo a capacidade de reconhecer e selecionar as fontes de informação relevantes para uma pesquisa. Com o advento e divulgação da Internet em meados dos anos 1990, passou-se falar em alfabetização midiática, que abarcava a competência analítica dos navegantes da web, para analisar, criticar, filtrar e interpretar a informação acessada, e a capacidade de participar ativamente da produção de novos conteúdos (inicialmente textos com a web 1.0 e mais tarde imagens, vídeos, áudios e animações, com a web 2.0). Na virada do milênio, todas essas definições variadas confluíram no conceito de letramento digital, que, segundo Soares (2002), define o estado ou a condição de quem aprendeu as novas práticas de leitura e escrita, agora desdobradas em novas possibilidades digitais, para além da utilização meramente técnica do aparelho 
tecnológico. Afirma a autora que a leitura e a interpretação de mensagens formuladas em diferentes formatos dependem em grande parte de experiências pessoais, origens culturais e níveis de maturidade, elementos que o usuário deve ser capaz de explorar, para canalizar suas habilidades técnicas em uma busca de sentido.

Assim, o letramento consiste em um processo que se estende pela vida inteira do indivíduo e que exige dele um exercício de adaptação constante ao contexto sociocultural e às novas linguagens. Dessa afirmação, percebemos que o letramento não termina com a aprendizagem do sistema de escrita e leitura: também o compõem as práticas sociais de ler e escrever, assim como os contextos em que elas se dão. Seguindo essa reflexão, percebemos que ser letrado para o uso de TICs significa desenvolver não apenas habilidades técnicas, mas uma abordagem autônoma para o uso dos recursos disponíveis. Percebemos ainda que "diferentes tecnologias de escrita criam diferentes letramentos" (SOARES, 2002, p. 155). Com efeito, um letramento realmente inovador é aquele que não se limita a transferir para uma nova tecnologia as mesmas atitudes, mas que impulsiona novas práticas, novas condutas ou mesmo novos valores socioculturais e novas formas de pensar (LANKSHEAR; KNOBEL, 2007; LEU et al., 2013).

De acordo com a análise de van Dijk (2005), o letramento digital constitui-se de três tipos de habilidades:

(1) Operacionais: o conjunto de habilidades técnicas que permitem manusear as TICs, acessando aplicações on-line e off-line (por exemplo, o editor de texto, o e-mail, as atividades de busca on-line).

(2) Informacionais: habilidades para procurar, avaliar e elaborar as informações disponíveis em rede.

(3) Estratégicas: habilidades para determinar objetivos específicos orientados a alcançar outras metas mais amplas, com o fim de manter ou melhorar sua própria realidade social.

Observa-se que a chegada da tecnologia móvel na sala de aula provoca em parte dos docentes a sensação de estar sendo desautorizado, por não ter familiaridade com a técnica, que os alunos manejam tão habilmente, e por ter de concorrer com os estímulos ofertados pelo mundo digital (PISCHETOLA; HEINSFELD, 2018). Porém, acreditamos que em uma perspectiva que entende a inclusão digital como desenvolvimento de habilidades que vão além da mera aptidão técnica, o acesso físico e material à tecnologia não é suficiente para gerar mudanças significativas (PISCHETOLA, 2016). De um ponto de vista geracional, os alunos parecem ser considerados como "nativos digitais" por terem crescido com a Internet e as TICs. Porém, isso não significa que eles contem com habilidades informacionais e estratégicas de uso da tecnologia. Ou seja, sem a ação mediadora do professor não há inclusão digital de alunos, da mesma forma como não há inclusão social, política ou democrática.

No mundo on-line, convergem informação e entretenimento, trabalho e lazer, local e global, público e privado. Diante dessa convergência, os sujeitos precisam desenvolver habilidades muito além das que já possuem em relação às dinâmicas de colaboração, acesso à informação em múltiplos formatos, produção de conteúdos e comunicação nos diferentes espaços de mediação. A nossa hipótese é que o conceito de "nativos digitais", em sua significação restrita de "sujeitos que manuseiam facilmente as tecnologias", não dá conta de explicar todas as dimensões mencionadas, apesar de ser utilizado como sinônimo de "jovens letrados digitalmente" por pais e professores.

Na próxima seção apresentamos uma pesquisa que visou investigar a percepção dos professores sobre as habilidades de seus alunos com relação ao uso de tecnologias. 


\section{Eles já nascem sabendo e sabem mais do que nós!}

Com intuito de melhor compreender as percepções dos professores da Educação Básica com relação às práticas de seus alunos quanto às tecnologias digitais, optamos por uma pesquisa de cunho qualitativo, cujo enfoque se dá na compreenção das interpretações de mundo que possuem os atores sociais, uma vez que é a partir delas que se constitui o próprio mundo social. A pesquisa qualitativa visa descrever uma determinada realidade, a fim de analisar as representações construídas nas relações humanas e os mais profundos significados que circulam em determinado contexto social. Nesse sentido, apresenta a possibilidade de reconstruir o sentido dos fenômenos observados, a partir da interpretação do pesquisador, relacionados com um sistema mais amplos de significados (BAUER, GASKEL, 2002; MARCONDES, 2010).

Realizada entre 2014 e 2016, a pesquisa tem como conjunto de evidências 64 entrevistas semiestruturadas com professores de oito escolas de ensino fundamental da rede municipal do Rio de Janeiro. As escolas campo da pesquisa - situadas em áreas da cidade com diferentes contextos socioculturais - foram indicadas pela Secretaria Municipal de Educação por sua relevância no âmbito de projetos e práticas pedagógicas que envolvessem o uso de TICs.

Para a coleta de dados, optou-se pelo instrumento da entrevista, que conforme Duarte (2004), é de grande utilidade e importância quando se objetiva mapear crenças, práticas, valores e sistemas classificatórios de universos sociais específicos. Segundo a autora, o uso desse instrumento permite, ainda, delimitar contradições e conflitos não claramente explicitados. Por essa razão, entendemos que se trata de um instrumento qualificado para a realização dessa pesquisa.

Para análise dos dados, tomamos como base a Teoria Fundamentada em Dados, de Glaser e Strauss (1967), que procura gerar explicações possíveis para os achados dentro de um contexto social de estudo, a partir dos dados produzidos em campo. Essa metodologia prevê a segmentação das falas dos entrevistados em unidades de significação, que são analisadas minuciosamente, interpretadas e sucessivamente reagrupadas por categorias de análise. No nosso caso, as unidades de texto retiradas das entrevistas que tiverem relação com o conceito de "nativismo digital" foram agrupadas sob esse indexador, tendo por objetivo a formulação de hipóteses explicativas do problema investigado. Com o intuito de dialogar com as pesquisas anteriores e a literatura sobre letramento digital, as entrevistas foram analisadas de acordo com a descrição de habilidades proposta por van Dijk (2005). Assim sendo, a pesquisa visou identificar e analisar as percepções dos professores quanto às novas gerações de alunos e seu uso de tecnologias digitais; quanto às características relacionadas ao "nativismo digital"; e quanto às habilidades consideradas por esses professores como essenciais para um uso eficaz e significativo dessas tecnologias. Selecionamos, a seguir, alguns recortes das falas dos docentes que nos auxiliaram nessa compreensão.

\subsection{Eles já nascem sabendo}

A visão preponderante nas falas dos docentes no que diz respeito à relação dos jovens com as tecnologias digitais dá ênfase não somente a sua familiaridade com essas tecnologias, mas ao fato de os jovens "já nascerem sabendo" como lidar com os mais variados dispositivos. Assim, os docentes atribuem essas habilidades a uma espécie de inatismo, ou seja, os jovens do século XXI seriam uma geração de pessoas que nasceram com habilidades diferenciadas, que garantiriam a proficiência no uso desses dispositivos. Tal descrição se mostra intimamente ligada ao conceito de "nativismo digital", conforme inicialmente proposto por Prensky (2001). 
[...] Na mesma hora eles sabem. Então eles têm essa sede. Eu acho que já vem no DNA, eu não sei. E em relação à mídia, eu acho que com dez anos eles já estão lá na frente. Né? (P13: 02.05)

Então, eu vejo que é uma relação extremamente importante, porque as gerações que vem agora dos alunos, já estão inseridos. Eu costumo até brincar com eles, dizendo que eles estão nascendo com chip. Então, já nascem inseridos nisso, já mexem com as tecnologias, e com as mídias de maneira geral, eles já mexem com muita fluência. (P58: 08.03)

Sempre, porque a primeira coisa que a gente fala é o seguinte: eles hoje nascem conectados, eles já nem enxergam o mundo sem um celular, um tablet, um computador portátil. (P29: 04.05)

[...] Hoje em dia, essa geração já nasce mexendo em botõezinhos, seja no computador, na televisão, no rádio, no aparelho de som em casa, no jogo... (P04: 01.04)

É possível perceber que a fluência destacada pelos professores diz respeito, majoritariamente, à habilidade técnica. Sob essa perspectiva, basta que os alunos saibam "mexer em botõezinhos", independente do aparato tecnológico utilizado, para serem considerados proficientes. Ou seja, ligar e desligar computadores, tablets e smartphones e fazer downloads de softwares e aplicativos diversos parecem ser compreendidas como habilidades suficientes para que esses jovens sejam considerados letrados digitalmente. Contudo, a habilidade técnica apenas contempla aquilo o que van Dijk (2005) define como habilidade operacional, o primeiro e o mais básico dos três elementos que compõem o letramento digital, como veremos mais adiante.

\subsection{Eles sabem mais do que nós}

A mesma visão parece ganhar ainda mais força quando os docentes comparam as habilidades dos alunos às suas próprias. Todavia, novamente percebemos que os relatos se restringem às habilidades operacionais, isto é, ao mero domínio da técnica.

Eu acho que eles sabem usar as mídias. As mídias mais atuais, mais modernas, até mais que a gente. [...] eles sabem muito mais até do que o professor e do que a escola oferece. (P07: 01.07)

Outro mundo, né, o que a gente tem que se acostumar a ele, porque eles estão aí, né, eles já sabem, muitos de nós ainda não estão, muitos de nós temos dificuldades, eles não, eles já nasceram nessa época. (P24: 03.08)

[...] eles mexem muito mais com as questões de mídia do que eu mesmo, né? Entendem melhor isso do que eu próprio, de nós professores [que somos] de uma outra geração. Talvez os professores mais jovens... mas eu que já sou de uma geração bem anterior, não tenho tanto domínio quanto eles têm. Eles dominam muito bem isso. (P27: 04.03)

A diferença geracional é sempre marcada como uma barreira, uma defasagem incomensurável. Mais do que um simples comparativo, algumas falas refletem, ainda, grande insegurança por parte dos docentes quanto à relação com as tecnologias digitais. 
Como "imigrantes digitais", sentem-se incapazes de propiciar a esses jovens algum diferencial com relação às tecnologias.

Se o cara não sabe, ele vai se sentir inseguro porque todo mundo naquela sala sabe melhor que ele. Quando ele vai ligar o negócio e não sabe, o aluno fala: "oh, aperta o botão tal". (P16: 02.08)

[...] A escola não tem mais esse papel, em alguns casos, de apresentar grandes novidades nesse aspecto. Eles sabem muita coisa (P07: 01.07)

No entanto, destacamos como nesse cenário são desconsideradas, mais uma vez, as habilidades informacionais e estratégicas na descrição daquilo o que configura o letramento tecnológico. Essa restrição à habilidade operacional se mostra alarmante, uma vez que apenas o trabalho com habilidades técnicas não contempla questões e (res)significações relevantes trazidas pela incorporação das tecnologias digitais na educação, como as novas práticas de leitura e escrita, a transformação no conceito de autoria, o remix e os novos caminhos para produção, difusão e pesquisa de informações. Tão pouco é levada em consideração o desenvolvimento do pensamento crítico com relação a tais transformações. Assim, é priorizado o conhecimento da técnica, em detrimento da compreensão e produção do sentido com relação à mesma habilidade técnica. E a tecnologia torna-se um antagonista da escola, antagonista temível, pois, aparentemente, mais apta a ganhar a competição.

\subsection{Mas a mediação é fundamental}

Em nosso entendimento, para que sejam desenvolvidas e potencializadas as habilidades informacionais e estratégicas nos jovens do século XXI, o trabalho da escola com as tecnologias digitais não deve se extinguir em seu caráter operacional. Mais do que "apertar botões", o aluno deve ser estimulado a explorar os mais diversos caminhos oportunizados por essas tecnologias, investindo não somente na pesquisa e na avaliação das informações disponíveis em rede, mas também na produção, na (re)combinação e nos (re)arranjos dessas informações, na reflexão crítica, e em demais habilidades que favoreçam sua atuação cidadã. Sendo assim, buscamos nas falas dos professores elementos que se alinhassem a essa visão e que ressaltassem a importância do papel da escola e dos professores como mediadores desse processo.

Tem que ter alguma pessoa que oriente esse jovem no uso da internet. [...] Esse aluno tem que aprender a lidar com esse universo. Ele ainda não sabe muito. A gente que trabalha com os jovens percebe que eles ainda não sabem muito utilizar essa ferramenta. E acabam se expondo de maneira negativa, quando não deviam. (P05: 01.05)

Você vê que ele está o tempo todo em contato com a tecnologia, mas a questão do letramento corre por fora porque você precisa de um orientador, você precisa do professor para intervir. Para mostrar para ele como utilizar essas mídias a favor, em benefício próprio, no seu próprio processo de ensino aprendizagem. Coisa que ele não sabe fazer sozinho. Então, eu acho que [a mediação] é fundamental porque, repetindo, eles utilizam as mídias para situações muito específicas, mas eles não têm essa visão ampla do quanto os recursos tecnológicos podem ajudá-lo no seu processo de ensino e aprendizagem. Eles não têm em sua grande maioria essa visão nenhuma, eles precisam, sim, do professor como esse mediador. (P19: 03.03) 
E aí a minha prática caminha neste sentido de mostrar para o aluno como lidar com aquela informação. Como refletir sobre ela. Como ser crítico. (P38: 05.06)

Embora em número reduzido - apenas 14 dos 64 entrevistados evidenciaram em suas falas a importância da mediação -, a existência desses casos pode apontar para uma desejável ruptura com os discursos de senso comum, promovendo a reflexão sobre as práticas docentes e, a partir disso, sua transformação.

Percebemos, a partir da análise das falas dos professores, a emergência de dois desafios principais para a educação:

(1) Com relação ao processo de aprendizagem, fica claro que é preciso rever o conceito de letramento, para que seja capaz de abarcar as novas linguagens do mundo contemporâneo, na direção de um letramento digital. Como explicamos, esse é o conjunto de habilidades e "competências digitais" que vai permitir aos "nativos digitais" aproveitarem a mídia de forma crítica, consciente e personalizando a informação.

(2) Com respeito à escola, é preciso reformular o lugar do professor, a sua prática pedagógica e a relação que ele constrói com os alunos, convidando-o a tornar-se mais consciente das mudanças em curso. Ainda que os professores precisem se apropriar do letramento digital, sua tarefa não é a de ensinar os estudantes a utilizar as tecnologias. Mais uma vez, é preciso reconhecer que as possibilidades técnicas disponibilizadas não determinam, por si só, os comportamentos.

\section{Considerações finais}

A literatura sobre o conceito de letramento digital, às vezes afirmado no plural letramentos ou multiletramentos - destaca como as ações que o indivíduo realiza com o uso de TICs precisam de novas linguagens, novas habilidades que não estão contempladas no sentido clássico de alfabetização. A partir dessa visão, está posto um desafio para a escola, que vai muito além da simples utilização de tecnologias em sala de aula. Os jovens já têm a apropriação técnica de tecnologias, já sabem manuseá-las para acessar jogos, redes sociais e informação no Google. O que eles não sabem é o que está por trás de uma busca no Google (por exemplo, os primeiros resultados são os mais relevantes ou os mais clicados?) ou qual é o significado da aceitação dos termos de privacidade e dos cookies das redes sociais que acessam, ou ainda quais são as implicações éticas de copiar e colar os conteúdos encontrados on-line em um trabalho escolar. Em outras palavras, as implicações éticas, econômicas, sociais e políticas do uso de aplicativos, motores de pesquisa e plataformas on-line.

Precisamos superar a crença de que existe uma geração que sabe como utilizar as TICs porque já nasceu na época da sua difusão, por três motivos principais. Em primeiro lugar, porque é muito difícil afirmar que uma inteira geração - sem nenhuma contextualização geopolítica - teve acesso às mesmas oportunidades de acesso e exposição às tecnologias.

Em segundo lugar, acreditamos que é extremamente necessário trabalhar em direção a uma conscientização, por parte de adultos e jovens, de que a habilidade técnica não é sinônimo de letramento digital. No contexto do século XXI, nos parece claro que as TICs trouxeram mudanças sociais, econômicas, políticas e culturais, que se refletem em todas as esferas da vida humana. Também, não há dúvida de que o mundo está cada vez mais rápido e complexo. Porém, a chave de interpretação do mundo atual não pode 
ser a técnica, pois, como argumentamos, a habilidade de manejar os recursos informáticos é só uma parte, a mais básica e circunscrita, do letramento digital.

Por último, reiteramos a necessidade de a escola reconhecer o seu papel de mediação entre o jovem e a sociedade do seu tempo, buscando abrir espaços de diálogo e de redefinição das relações entre aluno e professor. Acreditamos que esse movimento permitirá superar o medo injustificado que o professor sente da técnica e do uso meramente instrumental da tecnologia.

\section{Referências}

BANNELL, R.; DUARTE, R.; CARVALHO, C.; PISCHETOLA, M.; MARAFON, G.; CAMPOS, G. Educação no século XXI: cognição, tecnologias e aprendizagens. Petrópolis/Rio de Janeiro: Vozes/Editora PUC, 2016.

BAUER, M. W.; GASKELL, G. Pesquisa qualitativa com texto: imagem e som: um manual prático. 2 ed. Petrópolis, RJ: Vozes, 2002, 516 p.

BRASILINO, A. Formação de Professores e a prática pedagógica com tecnologias: estudo da correlação na base TIC Educação 2014. Rio de Janeiro, 2017, 166p. Dissertação de mestrado - Departamento de Educação, Pontifícia Universidade Católica do Rio de Janeiro. Disponível em: < https://doi.org/10.17771/PUCRio.acad.31998>. Acesso em: 14 jul. 2018.

DAVIES, A.; ELDER, C. (Org.). Handbook of Applied Linguistics, New York: Blackwell, 2004, 886 p.

DUARTE, Rosália. Entrevistas em pesquisas qualitativas. In: Educar, Curitiba, n. 24, p. 213-225, 2004.

GATtI, B. A., BARRETO, E. S. de S. (Org.). Professores do Brasil: impasses e desafios. Brasília: UNESCO, 2009.

GEE, J. P. A situated sociocultural approach to literacy and technology. In: BAKER, E. A. (Ed.). The New Literacies: Multiple Perspectives on Research and Practice. New York: Guilford Press, p. 165-193, 2010.

GLASER, B.; STRAUSS, A. (1967). The Discovery of Grounded Theory. Strategies for Qualitative Research. Piscataway, NJ: Rutgers, 2006.

HEINSFELD, B. D.; PISCHETOLA, M. Cultura digital e educação, uma leitura dos Estudos Culturais sobre os desafios da contemporaneidade. Revista IberoAmericana de Estudos em Educação, Araraquara, v. 12, n. esp. 2, p. 1349-1371, ago./2017. Disponível em: <http://dx.doi.org/10.21723/riaee.v12.n.esp.2.10301>. Acesso em: 06mai. 2018.

LANKSHEAR, C. \& KNOBEL, M. (orgs.). A new literacies sampler. Nova York: Peter Lang, 2007.

LEMKE, J. L. Letramento metamidiático: transformando significados e mídias. Trab. Ling. Aplic., Campinas, v. 49, n. 2, p. 455-479, jul./dez. 2010. 
LEU, D.J.; FORZANI, E.; BURLINGAME, C.; KULIKOWICH, J.M.; SEDRANSK, N.; COIRO, J. \& KENNEDY, C. The new literacies of online research and comprehension: Assessing and preparing students for the 21 st century with common core state standards. In: NEUMAN, S.B. \& GAMBRELL, L.B. (orgs.). Quality reading instruction in the age of common core standards. The International Reading Association, 2013.

LIVINGSTONE, S. Internet literacy: a negociação dos jovens com as novas oportunidades on-line. MATRIZes, Ano 4 - $\mathrm{n}^{\mathrm{o}} 2$ jan./jun. 2011, p. 11-42.

MARCONDES, M. I. A observação nos estudos de sala de aula e do cotidiano escolar. in: MARCONDES, M. I.; TEIXEIRA, E.; OLIVEIRA, I. A. de (orgs.); Metodologias e técnicas de pesquisa em educação. Belém: EDUEPA, 2010.

NAUMANN, L.A.; PISCHETOLA, M. Práticas de leitura e autoria na perspectiva dos multiletramentos: relato de pesquisa em escolas municipais do Rio de Janeiro. Revista Nuances, v. 28. n.1 p. 127-146, 2017. Disponível em: $<$ https://doi.org/10.14572/nuances.v28i1.4739>. Acesso em:06 mai. 2018.

PISCHETOLA, M. Inclusão digital e educação: a nova cultura da sala de aula. Vozes, Petrópolis, RJ: 2016.

PISCHETOLA, M., HEINSFELD, B. D. Technologies and teacher's motivational style: A research study in Brazilian public schools [Tecnologie e stile motivazionale dell'insegnante: una indagine condotta nelle scuole pubbliche brasiliane]. Journal of Educational, Cultural and Psychological Studies, $n^{\circ}$ 17, 2018, p. 163-177. Disponível em: <http://dx.doi.org/10.7358/ecps-2018-017-pisc >. Acesso em: 20 jun. 2018.

PRENSKY, M. Digital Natives, Digital Immigrants Part 1. On the Horizon, v. 9, n. 5, p. 1-6, 2001. Disponível em: <https://doi.org/10.1108/10748120110424816>. Acesso em 10 mai. 2018.

. H. sapiens digital: From digital immigrants and digital natives to digital wisdom. Journal of Online Education, 5(3), p. 1-9, 2009. Disponível em: $<$ http://nsuworks.nova.edu/innovate/vol5/iss3/1>. Acesso em: 10 mai. 2018.

RIEDNER, D. D. T. Práticas pedagógicas e tecnologias digitais no ensino superior: formação inicial de professores e inovação na UFMS. Tese de Doutorado. PPGE/PUCRio, 2018.

SOARES, M. Novas práticas de leitura e escrita: letramento na cibercultura. Revista Educ.Soc., v.23, n.81, dez, p.143-160, 2002. Disponível em: $<$ http://www.scielo.br/pdf/es/v23n81/13935.pdf>. Acesso em: 10 mai. 2018.

VAN DIJK, J. The deepening divide. Inequality in the Information Society. Londres/Nova Delhi: Sage, 2005. 